\title{
PENGENALAN BARANG PADA KERETA BELANJA MENGGUNAKAN METODE SCALE INVARIANT FEATURE TRANSFORM (SIFT)
}

\author{
Ronny Makhfuddin Akbar ${ }^{1}$, Nani Sunarmi ${ }^{2}$ \\ ${ }^{1}$ Fakultas Teknik Universitas Islam Majapahit \\ ${ }^{2}$ Fakultas Teknik Universitas Islam Majapahit \\ Email: '1 ronnyma.ft@unim.ac.id, ${ }^{2}$ nani.ft@unim.ac.id
}

(Naskah masuk: 11 September 2018, diterima untuk diterbitkan: 05 November 2018)

\begin{abstract}
Abstrak
Menunggu dalam suatu antrian di supermarket sering terjadi dalam kehidupan sehari-hari. Antrian tersebut terjadi karena pada kasir mengharuskan setiap barang untuk dipindai satu per satu menggunakan barcode. Hal ini dapat diatasi dengan menggunakan aplikasi pengenalan atau deteksi barang berbasis pengolahan citra yang akan membantu mempercepat pada proses pemindaian barang pada kasir dengan memindai beberapa barang sekaligus pada kereta belanja dan menampilkan nama barang, harga barang, dan total belanja. Tujuan dari penelitian ini adalah menerapkan algoritma yang membantu kasir untuk mengenali barang pada kereta belanja dan menampilkan harga barang dengan hanya mengambil citra kereta belanja. Algoritma yang diusulkan untuk mendeteksi dan mengidentifikasi beberapa barang dengan pencocokan citra menggunakan Scale Invariant Feature Transform (SIFT). Dan algoritma yang digunakan untuk menyaring pencocokan citra yang salah menggunakan metode RANSAC serta untuk menghasilkan homography terbaik untuk memetakan kotak pembatas barang pada citra kereta belanja. Citra hasil menunjukkan posisi barang pada citra dengan informasi harga barang dan total belanja. Sistem ini dapat mengenali barang dalam citra kereta belanja dengan tingkat akurasi rata-rata $48.89 \%$ berdasarkan jumlah barang dan jarak pengambilan gambar. Tingkat akurasi 100\% terhadap jumlah barang pada kereta belanja sebanyak 2-4 barang pada jarak dekat $(30-60 \mathrm{~cm})$, tingkat akurasi $46.67 \%$ dengan jumlah 5-7 barang pada jarak sedang $(60-90 \mathrm{~cm})$, tingkat akurasi 0\% dengan jumlah 8-10 barang pada jarang jauh (lebih dari $90 \mathrm{~cm})$. Sistem ini juga dapat mengenali barang tumpang tindih dengan baik pada permukaan tertutupi $20 \%, 40,60 \%$, dan $80 \%$, serta mayoritas sistem hanya bisa mengenali barang dengan bentuk objek datar.
\end{abstract}

Kata kunci: SIFT, pengenalan objek, pencocokan citra, homography

\section{RECOGNITION OF ITEM IN A SHOPPING CART USING SCALE INVARIANT FEATURE TRANSFORM (SIFT) METHOD}

\begin{abstract}
Waiting in a queue at supermarkets often happens in everyday life. The queue occurs because the cashier requires each item to be scanned one by one using a barcode. This can be overcome by using an object recognition or detection application based on image processing that will help speed up the process of scanning item at the cashier by scanning several items at the same time on the shopping cart and display the name, price, and total amount of shopping. The purpose of this research was to apply an algorithm that helps the cashiers to recognize item on shopping carts and display the price of item by simply taking a image of a shopping cart. The algorithm proposed to detect and identify several items with image matching using Scale Invariant Feature Transform (SIFT). And the algorithm used to filter false match at image matching using RANSAC method and to produce the best homography to map the boundary box of item in the image of the shopping cart. The result image shows the position of the item in the image with information on the price of the item and total amount of shopping. This system can recognize items in the shopping cart image with an average of accuracy rate at $48.89 \%$ based on the number of items and the distance of image capture. Accuracy rate of $100 \%$ based on number of items in the shopping cart as much as 2-4 items at close distance $(30-60 \mathrm{~cm})$, accuracy rate of $46.67 \%$ with 5-7 items at medium distance $(60-90 \mathrm{~cm})$, accuracy rate of $0 \%$ with 8-10 items at far distance (more than $90 \mathrm{~cm}$ ). This system can also recognize well on overlapping items on the surface covered $20 \%, 40 \%, 60 \%$, and $80 \%$, and the majority of the system can only recognize items with flat object shapes.
\end{abstract}

Keywords: SIFT, object recognition, image matching, homography 


\section{PENDAHULUAN}

Menunggu dalam suatu antrian adalah hal yang sering terjadi dalam kehidupan sehari-hari. Dalam kasus ini dapat diambil contoh pada antrian kasir supermarket. Antrian tersebut terjadi karena pada kasir mengharuskan setiap barang dipindai satu per satu menggunakan barcode sehingga proses pemindaian menjadi lama. Hal ini dapat diatasi dengan menggunakan aplikasi pengenalan atau deteksi barang berbasis pengolahan citra yang dapat membantu mempercepat proses pemidaian pada kasir dengan memindai beberapa barang sekaligus serta menampilkan nama, harga, dan total belanja.

Deteksi objek atau barang adalah topik umum yang terdapat pada pengolahan citra dan komputer visi. Berbagai metode telah dikemukakan untuk mengekstrak informasi yang berguna dari citra seperti analisis berbasis warna dengan menganalisa histogram RGB dan HSV pada tingkat piksel per piksel (Gonzalez \& Woods 1992). Segmentasi citra menggunakan supervised dan unsupervised thresholding untuk mengklasifikasikan piksel dalam gambar sebagai latar depan atau latar belakang (Otsu 1979). Teknik pengolahan citra morfologi untuk menggali gambar dengan elemen penataan kecil untuk mendeteksi bentuk dan pola (Meyer \& Beucher 1990).

Namun, menggunakan metode pencocokan citra berbasis fitur adalah teknik yang cepat dan andal untuk mengidentifikasi objek dengan variasi warna, orientasi, ukuran dan bentuk. Untuk tujuan dan ruang lingkup penelitian ini, metode ini terbukti menjadi pendekatan yang tepat. Fitur dan deskriptor ditentukan dengan menggunakan algoritma Scale Invariant Feature Transform (SIFT) yang ditemukan oleh Lowe (Lowe 1999). Fitur dari citra barang di keranjang belanja dibandingkan dengan fitur dari sekumpulan database citra barang. Pencocokan fitur yang sesuai kemudian disaring oleh lokasi piksel dan objek yang diidentifikasi berdasarkan jumlah fitur yang cocok antara setiap database barang dan citra kereta belanja.

Tujuan dari penelitian ini adalah untuk mengambil citra barang di keranjang belanja untuk mengenali nama dan harga barang yang diambil dari database barang dengan menghitung total biaya daftar belanja. Ketika barang dikenali, maka barang tersebut akan ditambahkan ke daftar dan harganya akan ditambahkan ke total biaya.

Penelitian tentang pengenalan barang belanjaan dengan gambar dan video menggunakan SIFT yang menjelaskan bahwa masalah penggunaan gambar objek yang ditangkap dalam kondisi pencitraan ideal (di sini disebut in vitro) untuk mengenali objek di lingkungan alami (in situ). Salah satu kontribusi adalah database multimedia dari 120 produk belanja disebut GroZi-120. Untuk setiap produk, tersedia dua rekaman berbeda yang terdiri dari gambar in vitro yang diambil dari web dan gambar in situ diambil dari video camcorder yang diambil di dalam supermarket. Hasil penerapan tiga algoritma pengenalan / deteksi objek yang umum digunakan adalah pencocokan histogram warna, pencocokan SIFT, dan boosted Haar-like features ke dataset. Algoritma yang digunakan terhadap jenis produk dan kondisi pencitraan mengalami keberhasilan dan kegagalan, baik dalam hal tingkat pengenalan dan akurasi lokalisasi (Merler, dkk. 2007).

Penelitian tentang pengenalan barang belanjaan menggunakan smartphone yang menjelaskan bahwa solusi pengalaman berbelanja khususnya konsumen yang mengalami gangguan penglihatan. Sebuah sistem yang secara visual mengenali kelas produk dari daftar belanja pada gambar rak-rak yang diambil dengan smartphone di supermarket. Sistem ini terdiri dari tiga komponen, pertama mengenali teks secara otomatis yang berguna pada kemasan produk, seperti nama produk dan merk, dan membuat pemetaan katakata ke kelas produk berdasarkan kumpulan data produk belanja berskala besar. Saat pengguna mengisi daftar belanja, aplikasi secara otomatis menyimpulkan kelas produk masing-masing kata yang dimasukkan. Komponen kedua adalah pengenalan kelas produk saat pengguna menghadapi rak. Serta terdapat patch diskriminatif pada kemasan produk untuk membedakan antara kelas produk yang serupa secara visual dan untuk meningkatkan ketahanan terhadap perubahan desain produk secara kontinyu. Ketiga aplikasi terus meningkatkan akurasi pengenalan melalui pembelajaran aktif. (George, dkk. 2015).

Penelitian tentang kereta belanja pintar menggunakan RFID untuk pembayaran yang menjelaskan tentang sistem shopping cart yang memiliki fungsi untuk mengikuti pembeli berdasarkan pengenalan visual dan kontrol gerakan, dan fungsi untuk menerapkan pembayaran otomatis berbasis RFID. Kereta belanja yang diusulkan secara akurat dapat mengikuti pembeli dengan mengidentifikasi karakteristik warna dan bentuk gambar spesifik yang dipakai pembeli dan secara signifikan mempercepat proses pembayaran (Liu, dkk. 2016).

Penelitian tentang pencarian produk belanja melalui web menggunakan metode SURF yang menjelaskan tentang sistem meta search-engine untuk melakukan pencarian barang menggunakan citra query berupa barang produk dan berbasiskan konten dari beberapa situs e-commerce. Citra query yang tidak dikenali, kata kuncinya dicari melalui Google reverse image search engine pada situs $e$ commerce. Fitur yang digunakan dalam pencocokan query dengan produk adalah fitur tekstual, color histogram bin, dan keberadaan citra objek yang dicari menggunakan SURF descriptor. Pengujian menggunakan precision dengan dibatasi 20 barang atauPrecision@20 untuk memudahkan perhitungan evaluasi sistem. Sistem memberikan hasil yang baik 
dengan precision@20 dan recall hingga 1 dengan rata-rata precision@20 dan recall masing-masing sebesar 0,564 dan 0,608, namun juga bisa gagal dengan precision@20 dan recall sebesar 0. Hasil yang kurang baik dikarenakan pencarian nama barang pada situs e-commerce tersebut terlalu umum (Adikara, dkk. 2018).

Dari beberapa kegiatan penelitian dengan topik sejenis di atas, terdapat perbedaan dan kesamaan topik penelitian. Beberapa kesamaan dengan penelitian terdahulu antara lain secara garis besar terletak pada fungsi tujuan adalah pengenalan objek atau barang produk supermarket, serta menggunakan algoritma pencocokan fitur yaitu menggunakan metode SIFT dan SURF. Metode SIFT pada penelitian tersebut digunakan untuk pencocokan fitur pada dataset produk supermarket. Metode SURF pada penelitian tersebut digunakan untuk pencarian citra objek produk belanja. Dari kedua metode tersebut, metode SIFT lebih baik dalam pencocokan citra dibandingkan SURF, tetapi metode SURF jauh lebih cepat dalam proses pencocokan citra (Willy dkk. 2013). Oleh karena itu, pada penelitian ini menggunakan metode SIFT untuk digunakan pada pencocokan citra, dikarenakan banyaknya variasi barang, posisi, dan jarak yang berbeda dalam pengambilan citra kereta belanja. Sedangkan kontribusi pada penelitian ini dibandingkan dengan penelitian-penelitian sebelumnya adalah tambahan fungsi untuk mengenali letak barang dengan menampilkan informasi nama barang dan harga barang serta menghitung jumlah biaya belanja.

\section{METODE PENELITIAN}

Pada penelitian ini dibuat sistem pengenalan barang pada kereta belanja menggunakan metode Scale Invariant Feature Transform (SIFT) yang dirancang agar dapat mendeteksi barang di dalam kereta belanja dan menghitung harga barang serta total belanja pada citra digital kemudian mengenali barang tersebut dengan cara mencocokkan hasil ekstraksi fitur-nya dengan fitur citra barang yang sebelumnya sudah tersimpan di dalam database.

Gambar 1 menunjukkan gambaran umum sistem pengenalan barang pada kereta belanja yang dibuat. Tahap pertama yaitu pengumpulan data citra yang digunakan sebanyak 50 citra kereta belanja yang digunakan sebagai data uji dan 91 citra produk barang yang digunakan sebagai data latih atau database dengan format JPG. Citra diambil dari supermarket di wilayah Kabupaten/Kota Mojokerto. Database barang terdiri dari 91 citra produk barang seperti sabun, makanan dan minuman ringan, kosmetik, dan bahan makanan. Barang dipilih berdasarkan variasi jenis, bentuk dan ukuran barang. Setiap barang pada kereta belanja mempunyai jumlah dan posisi yang berbeda-beda.

Tahap berikutnya yaitu ekstraksi fitur dari 91 citra barang yang disimpan dalam database dan digunakan sebagai citra referensi. Kemudian dilakukan ekstraksi fitur dari citra uji atau citra kereta belanja untuk kemudian dilakukan pencocokan fitur. Tahap selanjutnya yaitu mencari kecocokan fitur untuk tahap awal pengenalan barang pada citra kereta belanja. Setelah mendapatkan nilai kecocokan fitur, sistem mengurutkan database citra yang mendekati nilai kecocokan fitur pada citra kereta belanja dengan menggunakan metode RANSAC. Setelah diurutkan, maka sistem menerapkan homografi untuk menandai lokasi barang pada citra kereta belanja dengan membuat kotak pembatas. Setelah ditandai dengan kotak pembatas, sistem akan menyimpan informasi produk dan lokasi titik tangah kotak pembatas, kemudian menghapus fitur yang cocok dari daftar barang yang sudah dikenali, kemudian proses pengenalan diulang sampai semua barang dikenali. Tahap akhir adalah perhitungan total harga dan menampilkan informasi nama dan lokasi produk pada citra kereta belanja.

\section{HASIL DAN PEMBAHASAN}

Pada penelitian ini, menggunakan tools MATLAB untuk menganalisa data dan library VLFeat untuk menghitung fitur SIFT dan deskriptor. Pada pengambilan citra uji, jarak sudah ditentukan berdasarkan jumlah barang sebagai berikut: dekat 30$60 \mathrm{~cm}$ dengan jumlah 2-4 barang, sedang 60-90 cm dengan jumlah 5-7 barang, jauh lebih dari $90 \mathrm{~cm}$ dengan jumlah 8-10 barang. Jarak terbaik agar barang dapat dikenali oleh sistem adalah ketika barang dapat terlihat secara keseluruhan oleh kamera, selain itu dipengaruhi juga oleh besar-kecilnya barang (Sari

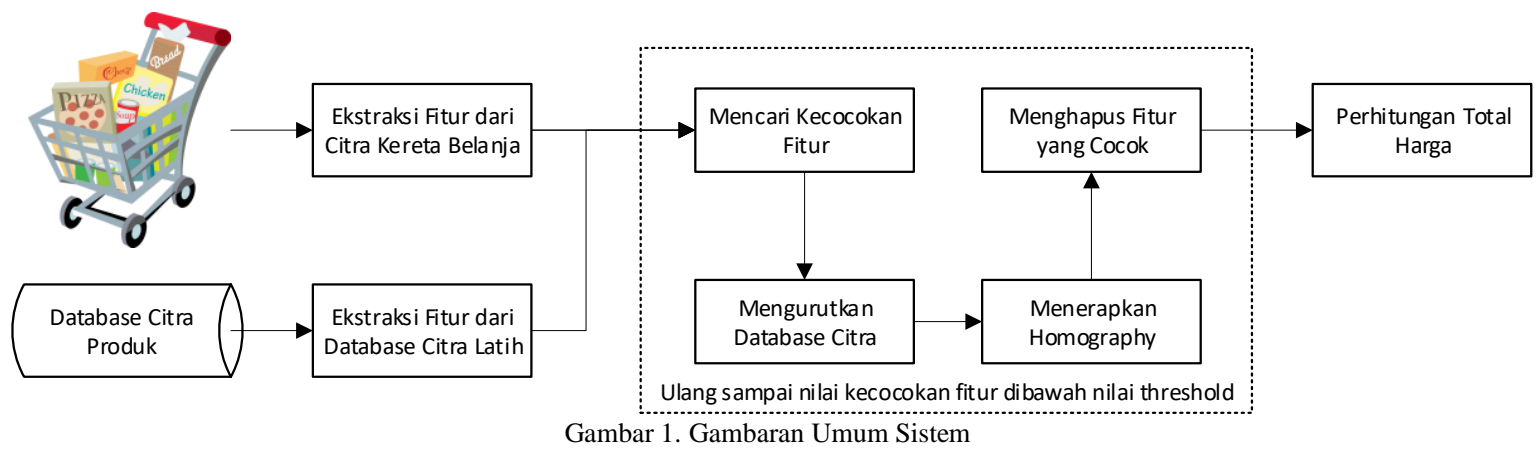


dkk. 2014). Berikut penjelasan tahapan penelitian yang dilakukan dan analisa pengujian nilai threshold, uji tumpang tindih, dan uji kepekaan pengenalan terhadap bentuk objek:

\subsection{Ekstraksi Fitur dari Database Citra}

Untuk membuat database citra, sistem akan mengekstrasi citra latih yang terdiri dari 91 citra produk mulai dari fitur SIFT, deskriptor, koordinat sudut piksel, nama dan harga barang yang dimasukkan ke dalam database citra, seperti pada Tabel 1 dan Gambar 2. Pada gambar 2, keypoint digambarkan sebagai lingkaran dengan tambahan garis untuk menunjukkan orientasi Ukuran lingkaran disesuaikan dengan area gambar yang digunakan untuk membuat deskriptor.

D. G. Lowe menyatakan bahwa algoritma SIFT adalah metode untuk mengekstrak dan mendeskripsikan titik-titik fitur, yang tahan terhadap skala, rotasi dan perubahan iluminasi. Ada empat langkah untuk menerapkan algoritma SIFT (Lowe 2004):

Langkah pertama, deteksi ruang skala ekstrema yaitu mencari ruang skala menggunakan fungsi Difference of Gaussian (DoG) untuk mengidentifikasi titik-titik yang diinginkan serta invarian terhadap skala dan orientasi. Ruang skala dari citra didefinisikan sebagai fungsi $\mathrm{L}(\mathrm{x}, \mathrm{y}, \sigma)$ pada persamaan (1) yang dihasilkan konvolusi variabel skala Gaussian $\mathrm{G}(\mathrm{x}, \mathrm{y}, \sigma)$ pada persamaan (2) dengan input citra $\mathrm{I}(\mathrm{x}, \mathrm{y})$ :

$$
\begin{aligned}
& L(x, y, \sigma)=G(x, y, \sigma) * I(x, y) \\
& G(x, y, \sigma)=\frac{1}{2 \pi \sigma^{2}} e^{-\frac{x^{2}+y^{2}}{2 \sigma^{2}}}
\end{aligned}
$$

Secara efisien untuk mendeteksi lokasi keypoint yang stabil dalam ruang skala menggunakan ruang skala ekstrema pada fungsi DoG yang dikonvolusi dengan citra, menggunakan persamaan (3) yang dapat dihitung dari perbedaan dua skala terdekat yang dipisahkan oleh faktor perkalian konstan k:

$$
\begin{aligned}
D(x, y, \sigma) & =(G(x, y, k \sigma)-G(x, y, \sigma)) * I(x, y) \\
& =L(x, y, k \sigma)-L(x, y, \sigma)
\end{aligned}
$$

Langkah kedua, lokalisasi titik fitur yaitu lokasi dan skala setiap titik kandidat ditentukan dan titik fitur dipilih berdasarkan ukuran stabilitas, informasi ini memungkinkan titik ditolak yang memiliki kontras rendah sehingga sensitif terhadap noise citra atau dilokalisasi dengan buruk sepanjang tepi citra.

Langkah ketiga, penentuan oriantasi, satu orientasi atau lebih ditempatkan ke masing-masing lokasi titik fitur berdasarkan arah gradien citra lokal. Untuk setiap citra pada skala L(x,y), gradien magnitudo $\mathrm{m}(\mathrm{x}, \mathrm{y})$ pada persamaan (6) dan orientasi $\theta(\mathrm{x}, \mathrm{y})$ pada persamaan (7) dihitung terlebih dahulu menggunakan perbedaan piksel pada persamaan (4) dan persamaan (5):

$$
\begin{aligned}
& L_{x}=L(x+1, y)-L(x-1, y) \\
& L_{y}=L(x, y+1)-L(x, y-1) \\
& m(x, y)=\sqrt{\left(L_{x}\right)^{2}+\left(L_{y}\right)^{2}} \\
& \theta(x, y)=\tan ^{-1}\left(\frac{L_{y}}{L_{x}}\right)
\end{aligned}
$$

Langkah keempat, deskriptor titik fitur, deskriptor fitur dibuat dengan terlebih dahulu menghitungnya besarnya gradien dan orientasi pada setiap titik citra di sekitar wilayah lokasi titik fitur. Citra ini kemudian diakumulasikan ke orientasi histogram dan dibagi menjadi $4 \times 4$ sub-region, dengan orientasi 8-bin. Jadi setiap fitur memiliki 128 elemen fitur.

Dengan menggunakan fungsi vl_sift, fitur yang diambil diberi nilai threshold / nilai ambang sehingga jumlah fitur maksimum per gambar tidak melebihi 3.000. Ini dilakukan untuk mengurangi waktu komputasi yang diambil selama langkah pencocokan. Threshold puncak dan tepi yang digunakan adalah 10 dan 7. Informasi yang diambil dari database citra ditentukan sebelumnya dan diimpor ke dalam MATLAB ketika algoritma tersebut diimplementasikan.

Tabel 1. Contoh Informasi Database Citra latih

\begin{tabular}{ccccc}
\hline \multirow{2}{*}{ Id\#\# } & \multicolumn{3}{c}{ Metadata } \\
\cline { 2 - 5 } & Nama & Harga & \#Fitur & Sudut Piksel \\
\hline \multirow{2}{*}{33} & Segitiga Biru & \multirow{2}{*}{10200} & \multirow{2}{*}{4730} & {$[117,240],[2749,240]$,} \\
& $1 \mathrm{Kg}$ & & & {$[2749,3759],[117,3759]$} \\
\multirow{2}{*}{34} & Agar Rasa & 2900 & 840 & {$[91,56],[983,56]$,} \\
& Strawberry & & & {$[983,1243],[91,1243]$} \\
41 & Sasa Tp & \multirow{2}{*}{5500} & 2462 & {$[219,228],[3007,228]$,} \\
& Bumbu Ori & & & {$[3007,3806],[219,3806]$} \\
42 & Sasa Tp Grg & \multirow{2}{*}{5500} & 2156 & {$[150,235],[2989,235]$,} \\
& Pisang & & & {$[2989,3806],[150,3806]$} \\
50 & Sedaap & 18300 & 1192 & {$[21,22],[794,22]$,} \\
& Kecap Manis & & & {$[794,1330],[21,1330]$} \\
\hline
\end{tabular}

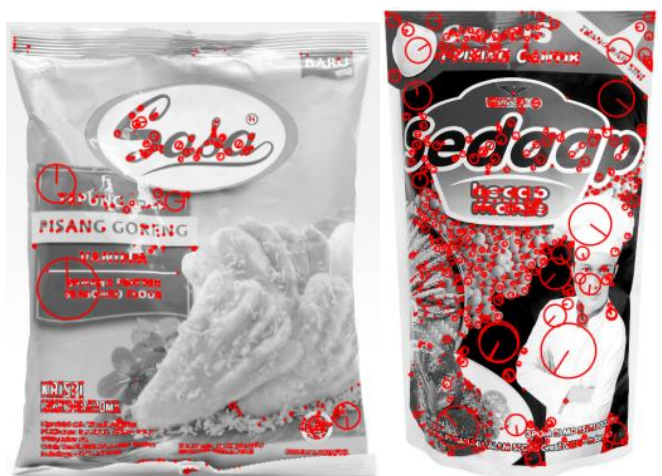

Gambar 2. Database Citra dengan Fitur SIFT 


\subsection{Ekstraksi Fitur dari Citra Kereta Belanja}

Fitur SIFT yang diekstraksi dari citra kereta belanja diberi nilai threshold menggunakan parameter yang sama seperti database citra. Gambar sampel ditunjukkan pada Gambar. 3. Pada gambar 3, terlihat tekstur atau rangka pada kereta belanja juga diekstraksi nilai fitur oleh sistem tetapi tidak disimpan dalam database citra.

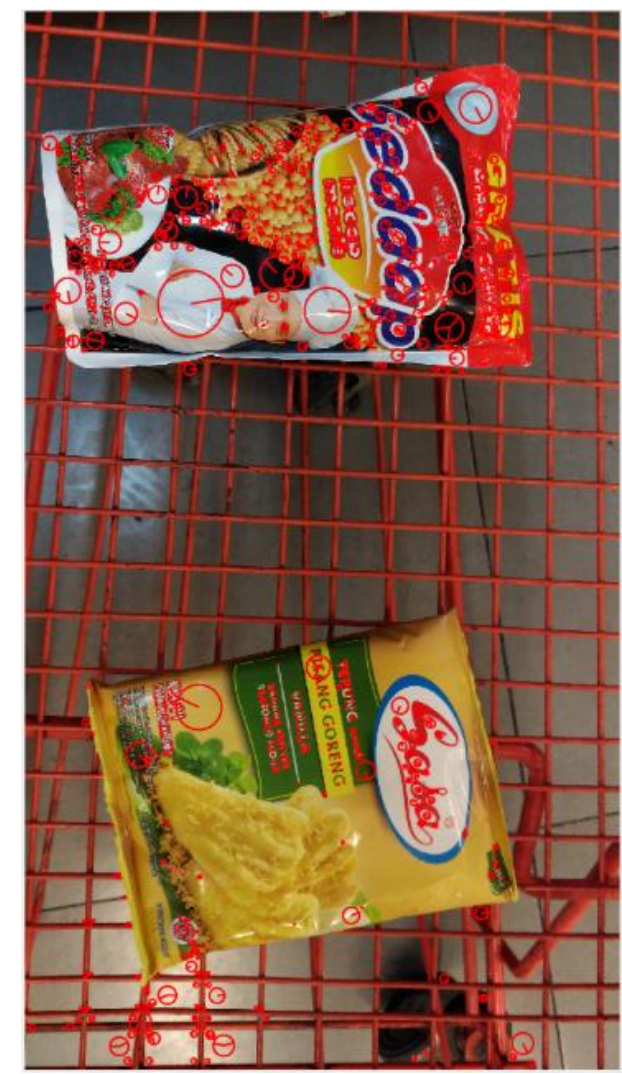

Gambar 3. Citra Kereta Belanja dengan Fitur SIFT

\subsection{Mencari Kecocokan Fitur}

Setelah memiliki informasi fitur dan deskriptor, sistem dapat melakukan kecocokan fitur yang sesuai. Deskriptor dalam setiap database citra dibandingkan dengan deskriptor dalam citra kereta belanja menggunakan perintah VLFeat yaitu vl_ubcmatch dengan nilai threshold 1,5 . Perintah ini mencocokkan deskriptor menggunakan pencarian tetangga terdekat (nearest-neighbour), yang didefinisikan sebagai keypoint dengan nilai minimum jarak Euclidean dalam ruang deskriptor. Setelah tahap pencocokan kemudian difilter lebih lanjut untuk menghapus fitur dalam database citra yang dicocokkan dengan satu fitur dalam citra kereta belanja. Gambar 4 merupakan hasil dari tahap pencocokan fitur, dan masih terlihat outlier atau kecocokan fitur yang salah (false match) dan inlier atau kecocokan fitur yang benar (true match).
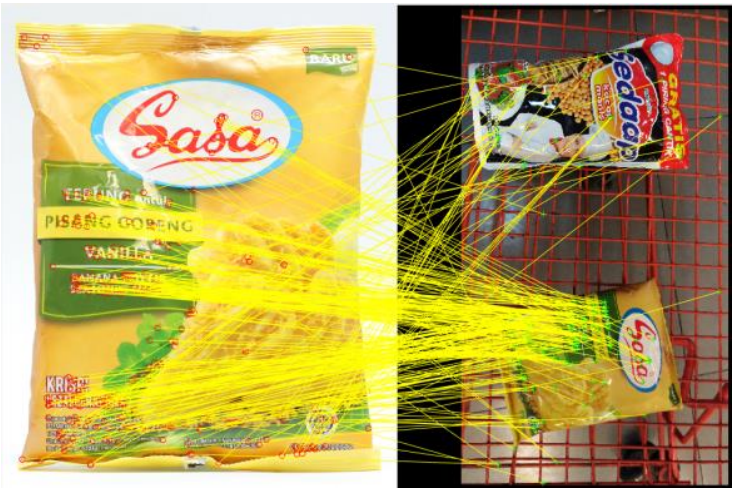

Gambar 4. Tahap Awal Pengenalan Barang (Pencocokan Fitur)

\subsection{Mengurutkan Database Citra}

Kemudian database citra diberi peringkat berdasarkan jumlah fitur yang cocok dengan setiap citra dengan citra kereta belanja. Untuk membuat pemetaan geometrik fitur yang akurat dari database citra teratas atau peringkat satu terhadap citra kereta belanja, pada penelitian ini menggunakan algoritma RANSAC digunakan untuk menghasilkan homografi dengan kemungkinan terbaik untuk memetakan kotak pembatas database citra ke citra kereta belanja (Fischler \& Bolles 1981).

RANSAC (Random Sample Consensus) merupakan prosedur untuk mengestimasi transformasi yang dialami oleh sebuah objek atau citra (Fischler \& Bolles 1981). RANSAC digunakan untuk menyaring false match yang masih banyak ditemui pada hasil pencocokan fitur. Cara kerja RANSAC adalah sebagai berikut:

1. Memilih 4 pasangan fitur secara acak.

2. Komputasi homografi $\mathrm{H}$ dari keempat fitur dengan DLT (Direct Linear Transform).

3. Proyeksi $\mathrm{x}$ ke $\mathrm{x}^{\prime}$ dengan $\mathrm{x}_{\mathrm{i}}{ }^{\prime}=\mathrm{Hx}_{\mathrm{i}}$

4. Hitung pasangan inlier antara $\mathrm{x}$ dan $\mathrm{x}^{\prime}$ dengan jarak kurang dari threshold.

5. Ulangi langkah diatas hingga $\mathrm{N}$-iterasi.

Untuk 100 iterasi, RANSAC menggunakan subset acak dari kecocokan fitur untuk menentukan homografi. Homografi terbaik dinilai dan dipilih yang terbaik dengan pasangan inlier yang paling banyak seperti terlihat pada Gambar 5 .
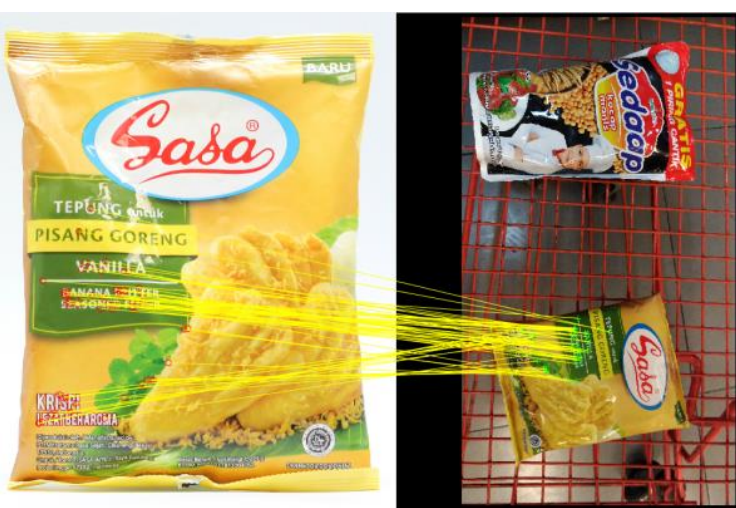

Gambar 5. Penerapan RANSAC untuk Menghilangkan Outlier 


\subsection{Menerapkan Homografi}

Setelah model homografi ditentukan, homografi diterapkan ke empat sudut dari database citra. Seperti ditunjukkan pada Gambar 6, mask biner dibuat yang memiliki dimensi yang sama dengan objek barang pada citra kereta belanja. Koordinat transformasi digunakan untuk membuat kotak pembatas di lokasi item yang cocok dalam citra kereta belanja. Kemudian dihitung titik pusat dari kotak pembatas dan disimpan. Piksel yang berada di dalam kotak diberi nilai 0 dan yang berada di luar diberi nilai 1 . Mask dan citra kereta belanja kemudian digabungkan untuk menghasilkan citra kereta belanja baru.

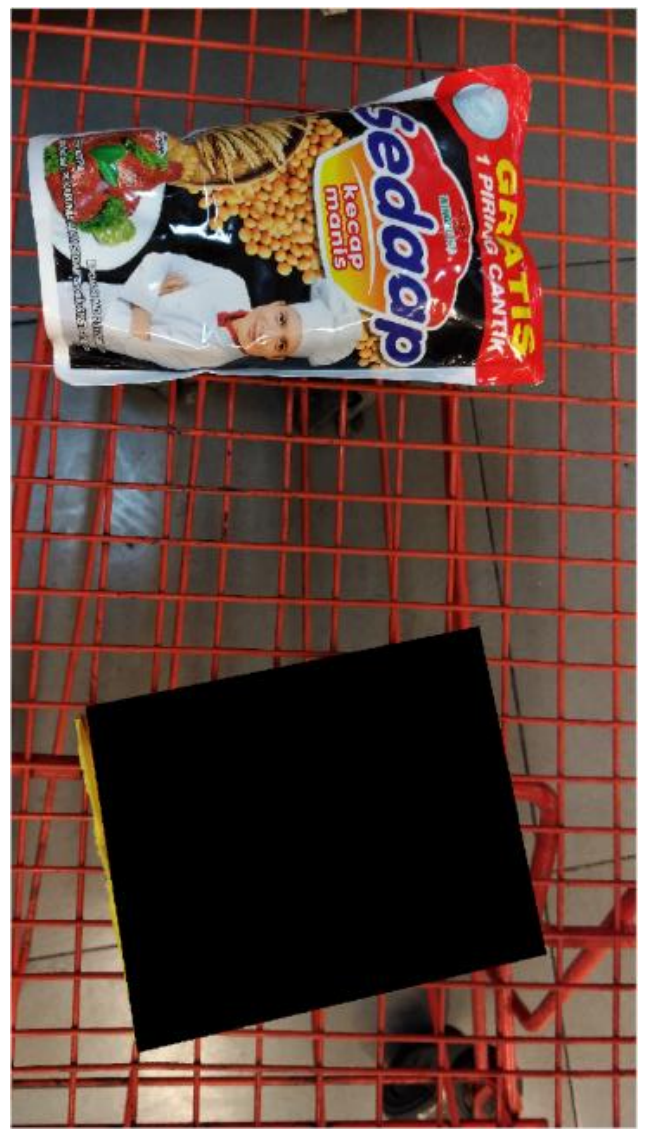

Gambar 6. Transformasi Koordinat dan Kotak Pembatas

\subsection{Menghapus Fitur yang Cocok}

Pada tahap ini, harga, nama barang, dan koordinat centroid / titik pusat kotak pembatas diambil dari database citra dan dihapus dari peringkat. Untuk setiap database citra tersisa, fitur yang cocok terletak di kotak hitam citra kereta belanja dihapus. Dengan berkurangnya jumlah fitur yang cocok, database citra diperingkat kembali dan prosesnya diulang. Tahap mengurutkan database citra sampai menghapus fitur yang cocok pada kotak pembatas diulang sampai jumlah kecocokan dari database citra peringkat atas, turun di bawah threshold yang ditetapkan secara empiris ke nilai 86 . Setelah database citra memliki jumlah total fitur yang cocok di bawah threshold, proses berhenti dan hasil dari algoritma dikembalikan.

\subsection{Perhitungan Total Harga}

Total harga semua barang yang terdeteksi dijumlah dan ditampilkan pada hasil citra. Setiap nama item dan harga setiap barang ditampilkan pada posisi centroid mereka. Gambar 7 menunjukkan contoh output dari algoritma.

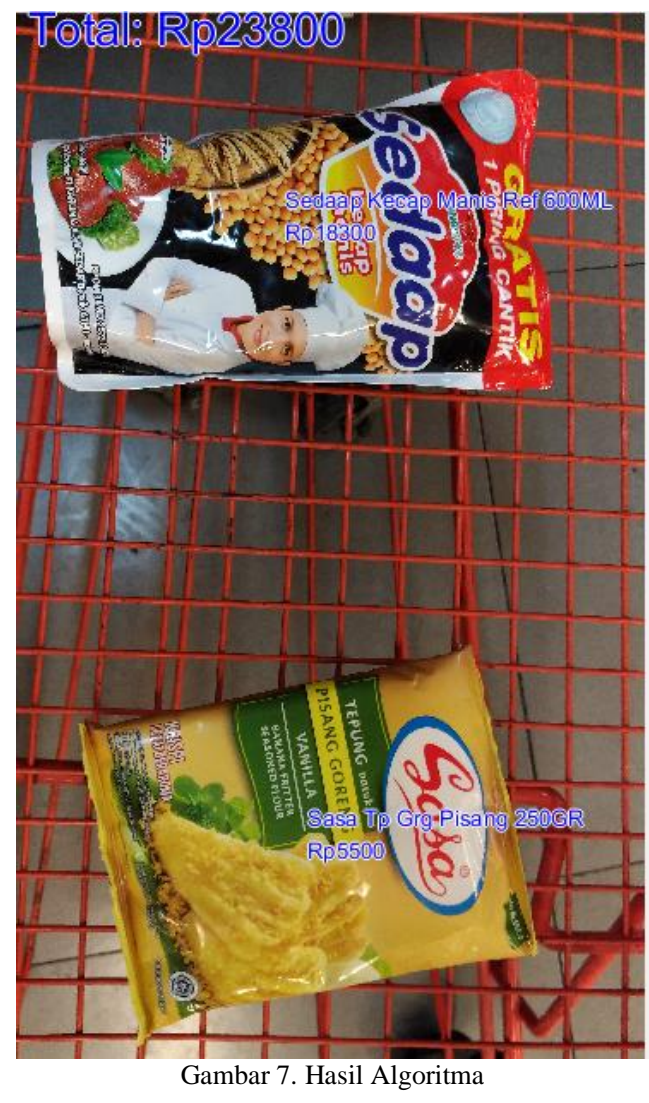

\subsection{Uji Nilai Threshold}

Tingkat akurasi didefinisikan ketika semua barang terdeteksi dengan benar, terlepas dari nilai threshold yang dipilih. Misal, jika citra kereta belanja memiliki 4 barang didalamnya, hasilnya akan dianggap akurat ketika 4 database citra teratas sesuai dengan barang dalam citra kereta belanja. Dikatakan gagal ketika database citra tidak terdeteksi dengan benar dalam citra kereta belanja tetapi terdapat pada 4 database citra teratas. Selanjutnya, nilai threshold yang digunakan untuk menentukan nilai rata-rata threshold sesuai dengan jumlah terendah kecocokan fitur barang yang berhasil dideteksi. Misal, citra kereta belanja dengan 4 barang dengan jumlah nilai rata-rata threshold kecocokan fitur adalah 75.28. Tabel 2 menunjukkan tingkat akurasi algoritma sebagai fungsi dari sejumlah barang dalam keranjang belanja. Jumlah citra pada tabel 2 menunjukkan jumlah citra kereta belanja yang diujikan per jumlah barang pada kereta belanja. 


\begin{tabular}{|c|c|c|c|c|}
\hline $\begin{array}{l}\text { Jumlah } \\
\text { Barang }\end{array}$ & $\begin{array}{c}\text { Jumlah } \\
\text { Citra }\end{array}$ & $\begin{array}{l}\text { Tingkat } \\
\text { Akurasi }\end{array}$ & $\begin{array}{l}\text { Rata-Rata } \\
\text { Threshold }\end{array}$ & $\begin{array}{l}\text { Standar } \\
\text { Deviasi }\end{array}$ \\
\hline 2 & 10 & $100 \%$ & 82.3 & 30.73 \\
\hline 3 & 10 & $100 \%$ & 81.3 & 17.78 \\
\hline 4 & 7 & $100 \%$ & 75.28 & 14.45 \\
\hline 5 & 5 & $100 \%$ & 64.2 & 13.98 \\
\hline 6 & 5 & $20 \%$ & 90 & 60.76 \\
\hline 7 & 5 & $20 \%$ & 56 & 23.1 \\
\hline 8 & 4 & $0 \%$ & 51.25 & 12.84 \\
\hline 9 & 2 & $0 \%$ & 38.5 & 9.19 \\
\hline 10 & 2 & $0 \%$ & 63 & 4.24 \\
\hline Rata-rata & & $48.89 \%$ & 66.87 & 20.79 \\
\hline
\end{tabular}

Hasil pengujian pada tabel 2 menunjukkan bahwa barang dapat dikenali $100 \%$ dengan jarak dekat atau 2-4 barang, pada jarak sedang atau 5-7 barang dapat dikenali dengan tingkat akurasi 46.67\%, sedangkan pada jarak jauh dengan jumlah 8-10 barang tidak dapat dikenali oleh sistem. Dari hasil tersebut sistem berhasil mengenali barang dengan rata-rata tingkat akurasi $48.89 \%$. Tingkat akurasi citra kereta belanja dengan jarak sedang dan jauh mengalami penurunan cukup drastis hingga $0 \%$. Tingkat akurasi yang menurun pada citra kereta belanja yang memiliki diatas 5 barang. Salah satu alasan menurunnya adalah meningkatnya jumlah barang pada citra kereta belanja. Citra kereta belanja dengan jumlah barang yang lebih sedikit diambil pada jarak yang lebih dekat dibandingkan dengan jumlah barang yang lebih banyak. Oleh karena itu, citra kereta belanja yang memiliki barang yang lebih sedikit memiliki kotak pembatas barang yang lebih besar. Hal ini menghasilkan hasil yang jauh lebih akurat karena pasangan outlier dari database citra yang tidak ada dalam citra memiliki kemungkinan lebih tinggi untuk disaring karena area piksel kotak pembatas yang banyak. Sebaliknya, citra kereta belanja dengan jumlah barang lebih banyak diambil pada jarak lebih jauh untuk menangkap citra barang keseluruhan, menghasilkan kotak pembatas barang yang lebih kecil. Kemungkinan penyaringan fitur yang salah akan berkurang karena ada lebih banyak piksel latar belakang dalam citra, sehingga penyaringan kurang efektif menggunakan pendekatan kotak pembatas.

Selain jarak berdasarkan jumlah barang, tingkat akurasi juga dipengaruhi oleh besar kecilnya barang. Dikarenakan semakin besarnya barang, pengambilan gambar juga lebih jauh agar terlihat dengan baik sehingga mempengaruhi tingkat akurasi barang. Menurunnya tingkat akurasi $100 \%$ pada jarak dekat ke $20 \%$ pada jarak sedang dikarenakan tidak semua barang dikenali dengan benar sehingga sistem dianggap gagal melakukan pengenalan barang. Pada citra kereta belanja yang memiliki 6 barang, dari 5 citra hanya 1 citra kereta belanja yang bisa mengenali semua barang dengan benar, misal pada gambar 8 dari 6 barang, hanya bisa mengenali 3 barang.

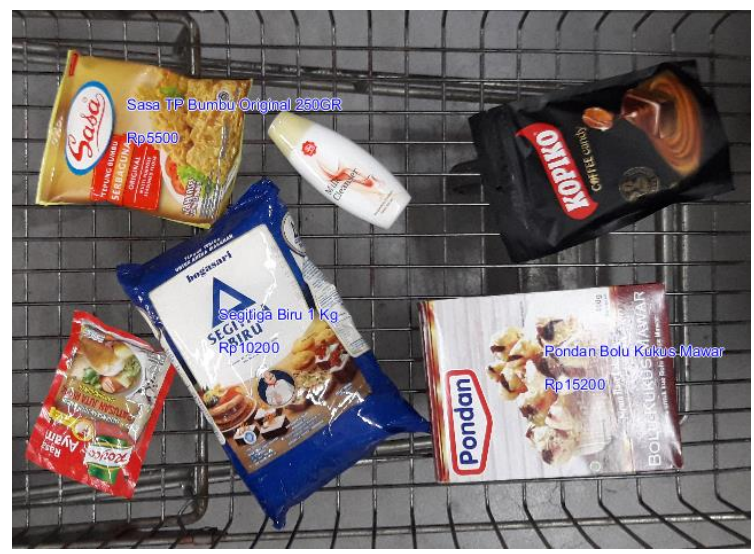

Gambar 8. Hasil Pengujian Uji Threshold yang salah

\subsection{Kepekaan Terhadap Tumpang Tindih Objek}

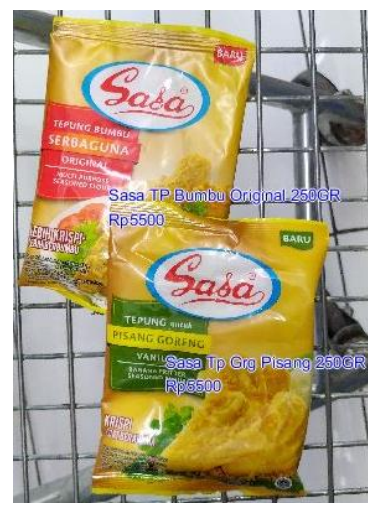

(a)

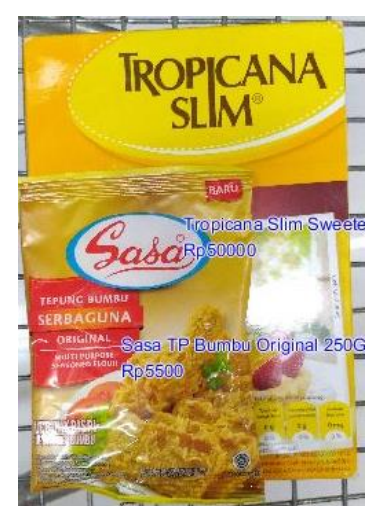

(b)

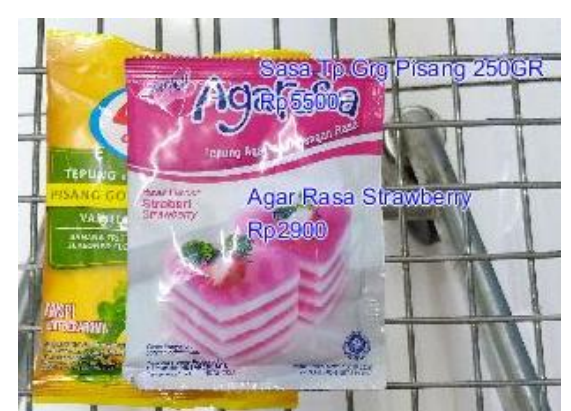

(c)

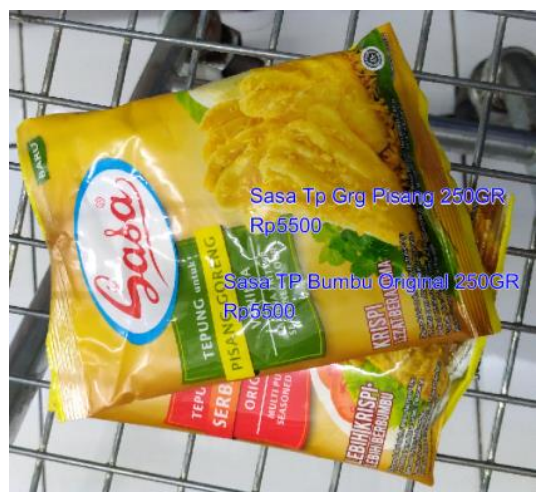

(d)

Gambar 9. Hasil Pengujian Barang Tumpang Tindih (a) 20\%, (b) $40 \%$, (c) $60 \%$, (d) $80 \%$ 
Pengujian terhadap tumpang tindih barang dilakukan untuk menguji kemampuan metode dalam mengenali tumpang tindih barang dengan permukaan tertutupi $20 \%, 40 \%, 60 \%$, dan $80 \%$. Pada gambar 8 , metode yang diusulkan berhasil mendeteksi objek yang tumpang tindih dengan tingkat akurasi $100 \%$. Keberhasilan mendeteksi barang yang tumpang tindih tergantung pada beberapa faktor. Pertama, persentase fitur di area yang tumpang tindih. Mayoritas fitur dari objek di bawah barang berada di area yang tidak tumpang tindih. Ini memungkinkan sebagian besar fitur dipertahankan dengan metode penyaringan kotak pembatas.

Kedua, algoritma sensitif terhadap urutan mendeteksi terhadap persentase barang yang tumpang tindih. Pada Gambar 9, objek bawah hanya terdeteksi jika memiliki jumlah nilai kemiripan fitur yang lebih besar daripada objek diatasnya. Ketika kasus tersebut terjadi, database barang yang di atas dihapus dari daftar sebelum barang yang di bawah, sehingga fitur tidak terhapus oleh metode penyaringan fitur. Ketika barang yang di bawah terdeteksi lebih dahulu, semua kecocokan fitur inlier dengan barang yang di atas dibuang karena berada di dalam kotak pembatas dari barang yang di bawahnya.

\subsection{Kepekaan Terhadap Bentuk Objek}

Hasil pengujian menghasilkan bahwa metode SIFT yang digunakan lebih akurat untuk mengenali objek dengan permukaan datar. Misalnya, produk minuman botol "NU Green Tea" seperti pada Gambar 10. Sehingga dapat disimpulkan bahwa semua fitur dari template citra diambil dari label depan barang. Setiap angular deviasi dari label depan template citra dapat mencegah kemampuan algoritma untuk melakukan pencocokan fitur.

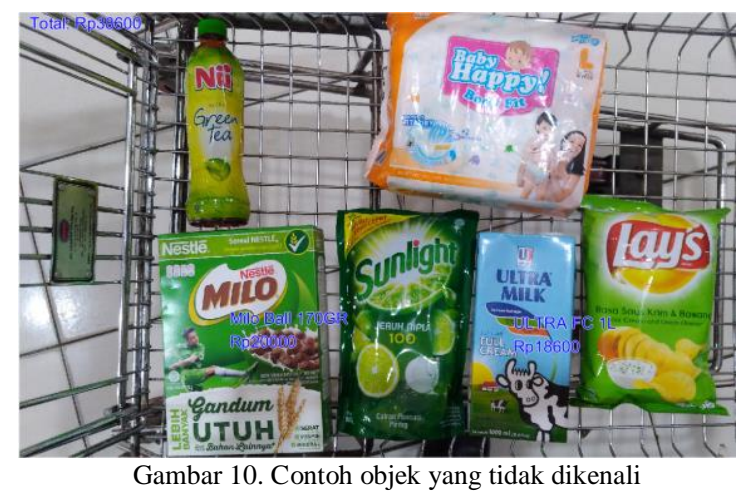

\section{KESIMPULAN}

Berdasarkan hasil pengujian yang telah dilakukan, sistem pengenalan barang pada kereta belanja menggunakan metode SIFT berhasil mengenali sejumlah barang dengan benar pada kereta belanja dengan menampilkan nama barang, harga barang, dan total belanja.

Pada pengujian threshold, Tingkat akurasi sangat baik pada jarak dekat atau 2-4 barang pada citra kereta belanja dengan akurasi 100\% dengan ratarata nilai threshold 75.28 sampai 82.3, pada jarak sedang atau 5-7 barang pada citra kereta belanja menghasilkan akurasi $46.67 \%$ dengan rata-rata nilai threshold 56 sampai 90, dan akurasi 0\% pada jarak jauh atau 8-10 barang pada citra kereta belanja dengan rata-rata nilai threshold 38.5 sampai 63. Dari hasil pengujian sistem berhasil mengenali barang dengan rata-rata tingkat akurasi $48.89 \%$.

Sistem juga berhasil mengenali barang dengan baik pada posisi tumpang tindih dengan permukaan objek bawah tertutupi 20\%, 40\%, 60\%, dan $80 \%$. Sedangkan terhadap bentuk barang, mayoritas sistem lebih akurat mengenali barang dengan bentuk objek datar seperti kemasan kotak dibandingkan dengan bentuk botol.

Penelitian selanjutnya disarankan algoritma diintegrasikan dengan fitur warna dan fitur tekstur sehingga dapat memperluas jenis barang yang akan dikenali misal pengenalan barang pada buah-buahan dan sayuran dikarenakan objek tersebut memiliki banyak variasi pada warna, bentuk, dan ukuran.

\section{UCAPAN TERIMA KASIH}

Ucapan terima kasih peneliti sampaikan kepada Direktorat Riset dan Pengabdian Masyarakat (DRPM) Dikti atas pendanaan penelitian dan publikasi penelitian dosen pemula (PDP) Tahun pelaksanaan 2018 dapat terlaksana dengan baik.

\section{DAFTAR PUSTAKA}

Adikara, P.P., Adinugroho, S. \& Sari, Y.A., 2018. Pencarian Produk yang Mirip Melalui Automatic Online Annotation dari Web dan Berbasiskan Konten dengan Color Histogram Bin dan Surf Descriptor. Jurnal Teknologi Informasi dan Ilmu Komputer, 5(1), p.104. Available at:

http://jtiik.ub.ac.id/index.php/jtiik/article/view/ 630.

Fischler, M.A. \& Bolles, R.C., 1981. Random sample consensus: a paradigm for model fitting with applications to image analysis and automated cartography. Communications of the ACM, 24(6), pp.381-395. Available at: http://portal.acm.org/citation.cfm?doid=35866 9.358692.

George, M. et al., 2015. Fine-Grained Product Class Recognition for Assisted Shopping. Proceedings of the IEEE International Conference on Computer Vision, 2015-Febru, pp.546-554.

Gonzalez, R.C.. \& Woods, R.E., 1992. Digital image processing. Nueva Jersey, p.796. Available at: http://web.ipac.caltech.edu/staff/fmasci/home/ astro_refs/Digital_Image_Processing_2ndEd.p df.

Liu, X. et al., 2016. Intelligent shopping cart with 
quick payment based on dynamic target tracking. Proceedings of 2016 4th IEEE International Conference on Cloud Computing and Intelligence Systems, CCIS 2016, pp.8893.

Lowe, D.G., 2004. Distinctive image features from scale invariant keypoints. International Journal of Computer Vision, 60, pp.9111020042. Available at:

http://portal.acm.org/citation.cfm?id=996342.

Lowe, D.G., 1999. Object recognition from local scale-invariant features. Proceedings of the Seventh IEEE International Conference on Computer Vision, pp.1150-1157 vol.2. Available at: http://ieeexplore.ieee.org/document/790410/.

Merler, M., Galleguillos, C. \& Belongie, S., 2007. Recognizing groceries in situ using in vitro training data. Proceedings of the IEEE Computer Society Conference on Computer Vision and Pattern Recognition.

Meyer, F. \& Beucher, S., 1990. Morphological segmentation. Journal of Visual Communication and Image Representation, 1(1), pp.21-46.

Otsu, N., 1979. A Threshold Selection Method from Gray-Level Histograms. IEEE Transactions on Systems, Man, and Cybernetics, 9(1), pp.6266. Available at: http://ieeexplore.ieee.org/document/4310076/.

Sari, I.P., Sulistyo, S. \& Hantono, B.S., 2014. Evaluasi Kemampuan Sistem Pendeteksian Objek Augmented Reality secara Cloud Recognition. Seminar Nasional Aplikasi Teknologi Informasi (SNATI), pp.1-6.

Willy, D., Noviyanto, A. \& Arymurthy, A.M., 2013. Evaluation of SIFT and SURF features in the songket recognition. 2013 International Conference on Advanced Computer Science and Information Systems, ICACSIS 2013, pp.393-396. 
Halaman ini sengaja dikosongkan 